\title{
Moderate Echinostoma trivolvis Infection Has No Effects on Physiology and Fitness-Related Traits of Larval Pickerel Frogs (Rana palustris)
}

\author{
Author(s): Sarah A. Orlofske, Lisa K. Belden, and William A. Hopkins
}

Source: Journal of Parasitology, 95(4):787-792. 2009.

Published By: American Society of Parasitologists

DOI: http://dx.doi.org/10.1645/GE-1840.1

URL: http://www.bioone.org/doi/full/10.1645/GE-1840.1

BioOne (www.bioone.org) is a nonprofit, online aggregation of core research in the biological, ecological, and environmental sciences. BioOne provides a sustainable online platform for over 170 journals and books published by nonprofit societies, associations, museums, institutions, and presses.

Your use of this PDF, the BioOne Web site, and all posted and associated content indicates your acceptance of BioOne's Terms of Use, available at www.bioone.org/page/terms_of_use.

Usage of BioOne content is strictly limited to personal, educational, and non-commercial use. Commercial inquiries or rights and permissions requests should be directed to the individual publisher as copyright holder. 


\title{
MODERATE ECHINOSTOMA TRIVOLVIS INFECTION HAS NO EFFECTS ON PHYSIOLOGY AND FITNESS-RELATED TRAITS OF LARVAL PICKEREL FROGS (RANA PALUSTRIS)
}

\author{
Sarah A. Orlofske* ${ }^{\star}$, Lisa K. Beldenł, and William A. Hopkins ${ }^{\star} \S$ \\ * Department of Fisheries and Wildlife, Virginia Tech, Blacksburg, Virginia 24061. e-mail: hopkinsw@vt.edu
}

\begin{abstract}
High intensity infections of Echinostoma trivolvis metacercariae decrease survival and growth of young amphibian larvae. However, in nature, parasites are highly aggregated, which results in a large proportion of the amphibian population being only moderately infected. Survival and growth responses at these more-common, low-infection levels remain poorly studied. Thus, we investigated the effects of moderate Echinostoma trivolvis metacercariae infection (following exposure to 0, 10, 30, or 90 cercariae) on the growth and development of pickerel frog (Rana palustris) tadpoles. We measured metabolism to determine whether increased energy expenditure is a potential physiological mechanism underlying previously documented reduced growth. Furthermore, we quantified tadpole intestine size, which can exhibit plasticity in response to changing metabolic demands, and we characterized metacercariae distribution in tadpole kidneys. Metacercariae encysted in the pronephros significantly more than in the mesonephros, but tended to occur equally in right and left kidneys. Two mo post-infection (PI), there were no changes in tadpole survival, development, intestine size, or growth related to metacercariae infection. Similarly, metacercariae did not significantly increase metabolic rates during encystment or at $1 \mathrm{mo}$ PI. Our study demonstrated that modest $E$. trivolvis infections, representative of a large proportion of the host population, had no detectable effects on fitness-related traits in laboratory isolation from other ecological variables.
\end{abstract}

Worldwide amphibian population declines and amphibian malformations have motivated a great deal of research on amphibian-parasite interactions (Johnson et al., 2001, 2002; Daszak et al., 2003). The trematode parasite Ribeiroia ondatrae, which infects larval amphibians as second intermediate hosts, has been linked with widespread limb malformations among a number of species (Johnson and Sutherland, 2003). Because of reduced survivorship of malformed amphibians, and the potentially impaired fitness of survivors, infection with $R$. ondatrae may contribute to amphibian population declines (Johnson et al., 1999; Johnson and Lunde, 2005). Echinostoma trivolvis, another trematode using larval amphibians as intermediate hosts, has also been a current research focus. Field studies characterizing parasitism in amphibian populations recently classified $E$. trivolvis metacercariae infection as a possible emerging disease of urban green frogs (Rana clamitans) because of the occurrence of high-intensity infections in some individuals (Skelly et al., 2006; Holland et al., 2007). In the laboratory, high infection levels $(>50$ metacercariae for a 1-time infection) of E. trivolvis can significantly reduce survival and growth in early developmental-stage tadpoles (e.g., Gosner developmental stage 24-25), particularly when recently hatched or within the beginning of early developmental stages (Gosner, 1960; Fried et al., 1997; Schotthoefer et al., 2003; Holland, 2007). However, macroparasites are often highly aggregated in nature, with a few individual hosts harboring high infections while the majority of the host population possesses much lower parasite burdens (Shaw et al., 1998). This aggregation of parasites likely occurs in populations of tadpoles, but the effects of more common, modest levels of infection on growth, development, and competitive ability have only recently been investigated (Koprivnikar et al., 2008) and require additional examination. Furthermore, seasonal timing of infection associated with amphibian life histories should also be addressed (Schotthoefer et al., 2003). The

Received 26 August 2008; revised 1 December 2008; accepted 9 January 2009.

$\dagger$ Present address: Department of Ecology and Evolutionary Biology, University of Colorado, Boulder, Colorado 80309.

†Department of Biological Sciences, Virginia Tech, Blacksburg, Virginia 24061.

$\S$ To whom correspondence should be addressed.

DOI: 10.1645/GE-1840.1 occurrence of infective cercariae will change throughout the developmental period of amphibians, often increasing throughout the season (Peterson, 2007). Thus, early developmental-stage tadpoles generally would have low infections while older, larger, more-developed tadpoles would have higher infections coinciding with peak cercariae abundance (Peterson, 2007). Such infections that occur later in larval ontogeny are an important consideration because sensitivity to E. trivolvis decreases with age and size (Schotthoefer, 2003; Holland, 2007).

The physiological impact of trematode infection on amphibians has also received limited attention (Martin and Conn, 1990; Holland et al., 2007). However, a change in growth and survival implies impairment of physiological or behavioral processes, or both. The renal inflammation induced by E. trivolvis metacercariae encysting within amphibian kidneys (Faeh et al., 1998) potentially disrupts kidney function. The presence of edema following cercariae exposure (Beaver, 1937; Fried et al., 1997; Holland, 2007) supports the notion that kidney dysfunction occurs following encystment of metacercariae (McClure, 1919). Encystment of $E$. trivolvis within kidneys is critical because this organ contributes significantly to the standard metabolic rate (SMR; the basal daily metabolism of a post-absorptive, resting ectotherm) of amphibians (Steyermark et al., 2005). Kidney dysfunction may lead to increases in metabolic demands that could impair growth. However, metabolism has rarely been characterized because metacercariae have frequently been considered a relatively metabolically inactive, dormant stage (Fried, 1997). In other systems where effects of metacercariae have been investigated, host metabolism has been altered. For example, newly acquired Uvulifer ambloplitis metacercariae increased the oxygen consumption of juvenile bluegill sunfish (Lepomis macrochirus) during encapsulation in the host muscle tissue (Lemly and Esch, 1984; Esch et al., 2002).

Higher metabolic rates caused by parasites may require hosts to spend additional time foraging to meet increased energy demands; however, phenotypic changes to increase the rate and efficiency of digestion may offset these increased feeding requirements. Tadpoles demonstrate remarkable plasticity in intestine size and length in response to predator presence and altered density (Relyea and Auld, 2004). Increasing the time food spends in the digestive system, by increasing the size of intestines, could increase digestive efficiency (Sibly, 1981). Organ size plasticity 
caused by parasitism has been documented in other taxa, including mammals (Kristan and Hammond, 2000; Schwanz, 2006), but has not been examined in amphibians.

To examine whether moderate E. trivolvis infection can affect amphibian physiology and fitness-related traits, we exposed pickerel frog (Rana palustris) tadpoles to 0-90 cercariae at ages and developmental stages that approximate natural transmission conditions. We monitored survival, growth, and development, as well as oxygen consumption, to determine whether infection alters metabolic demands. We also measured intestine sizes to determine whether phenotypic changes occurred in response to parasite infection. We also quantified encystment rates and location of metacercariae within the tadpole nephric system, factors which may differ based on initial infection level. Our prediction was that E. trivolvis metacercariae would raise the metabolism of infected tadpoles, and result in reduced growth and development, while also eliciting an increase in intestine size to compensate for increased energetic costs.

\section{MATERIALS AND METHODS}

\section{Parasite collection and maintenance}

On 11 April 2007 and 5 May 2007, E. trivolvis-infected Planorbella trivolvis snails were collected from a pond approximately $30 \mathrm{~km}$ from the Virginia Tech campus (Montgomery County, Virginia). Previous research at this location confirmed the identity of host and parasite species (Belden, 2006). Snails were maintained individually in 120-ml cups filled with $90 \mathrm{ml}$ of dechloraminated (ChlorAm-X ${ }^{\circledR}$, AquaScience Research Group, Inc., North Kansas City, Missouri) tap water at 22-24 C under diffuse overhead fluorescent lights. Snails were fed lettuce ad libitum, supplemented with Tetra-Min fish food (Tetra Holding U.S., Inc., Blacksburg, Virginia) (Schmidt and Fried, 1996a). Complete water changes occurred once a week. Echinostoma trivolvis infection was confirmed in the laboratory, immediately after collection, by placing individual snail cups $20 \mathrm{~cm}$ below a $60 \mathrm{~W}$ incandescent light bulb and microscopically examining the shedding cercariae (Schmidt and Fried, 1996b). Infected snails were maintained throughout the experiment (end of May, 2007) at a low temperature (15-17 C) to prevent shedding and re-infection of the snails by the emerging cercariae.

\section{Amphibian collection and husbandry}

In March 2007, 10 freshly laid $R$. palustris egg masses were collected from Arcadia, Virginia (Botetourt County) and transported to the laboratory in coolers. Individual egg masses were gradually transferred from pond water to a $3: 1$ mix of dechloraminated tap water $(62 \mathrm{mg} / \mathrm{L}$ $\left.\mathrm{CaCO}_{3}\right)$ and well water $(364 \mathrm{mg} / \mathrm{L})$. This mixture was necessary to reach acceptable hardness levels $\left(172 \mathrm{mg} / \mathrm{L} \mathrm{CaCO}_{3}\right)$

Ten fertilized eggs, with intact jelly coats, were separated from each egg mass and mixed to produce a group of 100 eggs. This procedure was repeated 10 times to produce 10 groups with similar genetic variation. The egg groups were maintained in 2-L glass beakers containing the same 3:1 mix of dechloraminated tap water and well water. Eggs hatched 12 days later, and the resulting tadpoles were examined for malformations. Sixtysix morphologically normal tadpoles from each of the original 10 groups were then transferred to 10 outdoor mesocosms, where they were maintained until they reached a size and developmental stage suitable for experiments (see next section for size and developmental stages used). Mesocosms were constructed from 1,500-L stock tanks filled to approximately 1,000 L of a 1:1 mixture of dechloraminated tap water and well water. Each mesocosm received $1 \mathrm{~kg}$ of air-dried oak leaf litter and $17 \mathrm{~g}$ of ground rabbit chow (Purina ${ }^{\circledR}$, LM Animal Farms $^{\circledR}$, The Hartz Mountain Corporation, Secaucus, New Jersey). Twenty-two days prior to introducing tadpoles to each mesocosm, aquatic communities were established by adding $1.5 \mathrm{~L}$ of filtered pond water. Filtration through a $200-\mu \mathrm{m}$ sieve excluded predators. Tanks were covered with plastic mesh to prevent colonization by either predators or competitors during the experiment.
All experimental procedures were performed in the laboratory on tadpoles collected from the mesocosms. During the experimental period, tadpoles were maintained at $22 \mathrm{C}$ in an environmental chamber with a 12:12-hr day:night cycle. Each tadpole was housed individually in a 4-L plastic shoebox randomly placed on shelves and filled with $2 \mathrm{~L}$ of dechloraminated tap water. Rations consisted of a 3:1 mixture of ground rabbit chow and Tetra-Min ${ }^{\circledR}$ Flake fish food in the amount of $10 \%$ of body mass per day. We expected a negative effect on growth and development at this feeding level because previous laboratory infection studies using similar (Holland et al., 2007), or more generous (ad libitum), rations (Fried et al., 1997) reported effects on survival, growth, and development. Every 2-3 days, 50\% water changes were performed.

\section{Experimental design}

Tadpoles for the laboratory experiment were selected from mesocosms at developmental stages 26-28 (Gosner, 1960; mean mass \pm SD $=0.46 \pm$ $0.07 \mathrm{~g}$ ) based on a high likelihood of successful parasite encystment (Schotthoefer et al., 2003). Four cercariae-exposure treatments were used: 0 (control), 10, 30, and 90 cercariae. However, respirometry measurements could only be completed on 8 individuals at a time. Therefore, we tested 2 individuals in each treatment, each day, for 6 consecutive days, ultimately producing 12 tadpoles per treatment for respirometry measurements. To obtain individuals for exposures, each day we collected a single tadpole from each of the 10 mesocosms. From this pool of 10 tadpoles, 8 were randomly chosen and 2 were assigned to each of the 4 cercariae-exposure treatments

Tadpoles were exposed to cercariae concurrently with oxygen consumption measurements. Treatment levels (10-90 cercariae) were unlikely to result in mortality and edema (Fried et al., 1997) and were within the lower end of the natural range of infections (Fried and Bradford, 1997; Skelly et al., 2006). Cercariae used for experiments were those shed from the snails in the morning corresponding to greatest shedding (Kanev et al., 1995), just prior to tadpole exposure. Cercaria shedding was induced by placing snails in small cups approximately $20 \mathrm{~cm}$ below a $60 \mathrm{~W}$ incandescent light bulb (Schmidt and Fried, 1996b). Appropriate numbers of cercariae were collected, using a glass pipette, and dispensed into $100-\mathrm{ml}$ glass culture bottles containing $80 \mathrm{ml}$ of aerated dechloraminated tap water to which a tadpole was then added. For the control treatment, tadpoles were added to bottles that did not contain cercariae. The bottle size and water volume were chosen to discourage evasive tadpole movement and to ensure maximal encystment rates (Kiesecker, 2002; Taylor et al., 2004; Belden and Kiesecker, 2005). Bottles were sealed and connected to a closed-circuit respirometer such that respirometry measurements began during encystment (see next section). Cercariae penetration may occur within $30 \mathrm{~min}$, and encystment generally occurs within $2.3 \mathrm{hr}$ (Penchenik and Fried, 1995; Fried et al., 1997).

\section{Amphibian energetics}

A repeated measures design was used to determine metabolic rates of individual tadpoles prior to infection, during exposure and encystment, and 1 mo post-infection (PI). Tadpole SMR were estimated from oxygen consumption rates $\left(\mathrm{O}_{2} \mathrm{ml} / \mathrm{hr}\right)$ measured on a computer-controlled, indirect, closed-circuit respirometer (Micro-Oxymax, Columbus Instruments, Columbus, Ohio). The instrument was calibrated using a certified air mixture prior to each trial. One standard control chamber contained a medical battery (Duracell Procell Zinc Air Medical, DA 1468.4 Volts, Proctor \& Gamble, Bethel, Connecticut) that consumed a known amount of $\mathrm{O}_{2}$. A second chamber, filled only with water, served as a blank. The standard and blank were used to verify the proper functioning of the instrument. Chambers were placed in an environmental cabinet maintained at $22 \mathrm{C}$ for the duration of the measurements. Micro Oxymax software (Columbus Instruments, Columbus, Ohio) was used to measure chamber volumes automatically, and leaks manually. The software was programmed to measure $\mathrm{O}_{2}$ consumption rates $(\mathrm{ml} / \mathrm{hr})$ within the chambers every $66 \mathrm{~min}$ and to correct for standard temperature and pressure. Prior to measuring $\mathrm{O}_{2}$ consumption rates $(\mathrm{ml} / \mathrm{hr})$, each air sample was dried using a hygroscopic drier containing nafion tubing (Columbus Instruments). Each respirometry trial lasted $24 \mathrm{hr}$, and air within the chambers was completely refreshed every $2.5 \mathrm{hr}$ to maintain normoxic conditions.

Tadpole respirometry trials began in the morning; the start time was standardized at $\sim 0900 \mathrm{hr}$ to account for the influence of the natural 
circadian rhythms on respiration of the tadpoles (Roe et al., 2004). Tadpoles were fasted for $48 \mathrm{hr}$ prior to each respirometry trial to reduce metabolic contributions from digestion (Crowder et al., 1998). Tadpoles were also blotted to remove excess moisture, and wet mass was recorded to the nearest $\pm 0.1 \mathrm{mg}$. To start each trial, 8 experimental animals ( 2 for each treatment) were randomly assigned to individual respirometry chambers, as described above.

Twenty-four-hour respirometry trials of each individual were conducted 3 times over the course of the study. We first measured the metabolic rate of all tadpoles assigned to each treatment before exposure to cercariae. After $24 \mathrm{hr}$ of feeding and then $48 \mathrm{hr}$ of fasting in the plastic shoeboxes, respiration of the same individuals was measured again with an identical procedure, but in the presence of infective cercariae (as described elsewhere). One month PI, the respirometry procedure was repeated for a third time.

To verify that the oxygen consumption measurements did not include any contribution from the parasites prior to penetration of the tadpole, identical experimental conditions were used to measure cercarial respiration in the absence of tadpole hosts $(\mathrm{n}=8$ trials per treatment level of 10,30 , or 90 cercariae). We determined that cercariae oxygen consumption $(\mathrm{ml} / \mathrm{hr})$ was low and statistically indistinguishable from water controls at any treatment level $(P=0.297)$.

\section{Survival, growth, and development}

The same tadpoles used for oxygen consumption measurements were raised individually for 2 mo PI, under laboratory conditions, to monitor survival, growth, and development. After $1 \mathrm{mo}$, the water volume was increased from the original $2 \mathrm{~L}$ to $3 \mathrm{~L}$ in order to accommodate larger tadpoles. Tadpole wet mass was recorded every 6 days to monitor growth and adjust food rations. The developmental stage of each tadpole was recorded prior to each respirometry measurement (pre-infection, during infection, and $1 \mathrm{mo}$ PI) and at the end of the experiment ( 2 mo PI)

\section{Dissection procedure and intestine measurements}

Two months PI, tadpoles were killed with MS-222 (ACROS Organics, Morris Plains, New Jersey) and immediately dissected. With the aid of a dissecting microscope (Fisher Scientific, Pittsburgh, Pennsylvania), organs were removed, in order from the ventral to dorsal surface, and wet mass of intestines was recorded. The tadpoles were fasted for $48 \mathrm{hr}$ prior to their death, which minimized the contribution of food to the mass of the intestine. Intestine length was measured to the nearest $\mathrm{mm}$. Intestines were frozen and subsequently dried to a constant mass for $48 \mathrm{hr}$ in a $60 \mathrm{C}$ drying oven.

All 4 kidneys (paired pronephros and mesonephros) and connecting Wolffian ducts were removed and examined for encysted $E$. trivolvis metacercariae with the aid of a compound microscope $(\times 20)$ (Carl Zeiss MicroImaging, Inc., Thornwood, New York). Wet mounts were prepared for light microscopy by pressing kidney tissue between a glass coverslip and slide after treatment with $10 \%$ chlorox (sodium hyperchlorite) for $3-$ 5 min to partially solubilize tissue (Penchenik and Fried, 1995).

\section{Statistical analysis}

Prior to statistical analysis, all data were examined to determine whether they met assumptions of parametric models. All statistical tests were conducted using either SAS 9.1.3, or JMP 7.0, (SAS Institute, Cary, North Carolina). Statistical significance was assessed at $\alpha=0.05$. To verify differences in number of parasites among treatment levels, but equivalent encystment rates among treatments, the total number and percent of metacercariae encysted in the kidneys were compared among the 10, 30, and 90 parasite treatments using ANOVA (PROC GLM). Although treatment levels were distinct, the variation in encystment within each treatment (see results) precluded categorical analysis for encystment in repeated measures ANCOVA. Instead, the number of metacercariae was treated as a continuous variable in regression models.

The number of tadpoles in each treatment surviving to the end of the 2 mo experiment was monitored. To assess whether infection influenced growth, the mass of tadpoles 2 mo PI was analyzed using a simple linear regression of mass and number of metacercariae. A multiple regression analysis was performed for developmental stage, tadpole mass, and the number of metacercariae 2 mo PI.

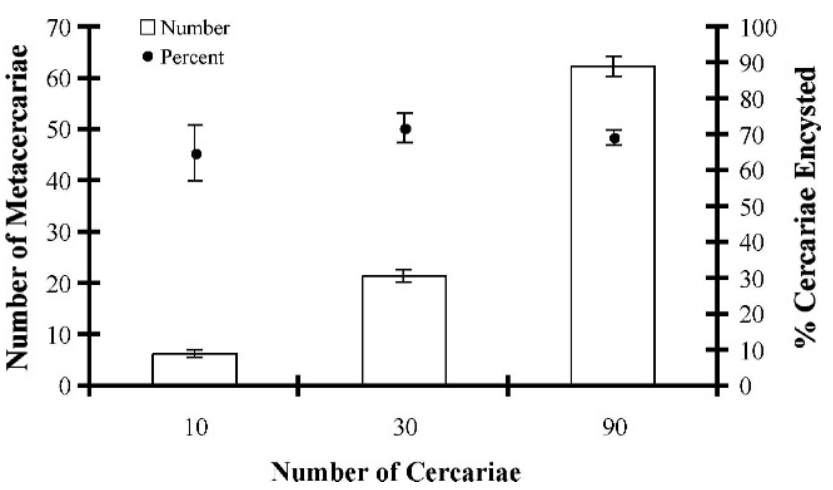

FIGURE 1. The mean number and percent of Echinstoma trivolvis metacercariae recovered from kidneys of Rana palustris tadpoles exposed to 10,30 , or 90 cercariae ( $\mathrm{n}=12$ per treatment). The raw number (bars) of metacercariae recovered is presented on the left axis. The number of metacercariae observed in the kidney, relative to the number of cercariae present at exposure, is indicated as a percentage (no. of metacercariae observed/no. of cercariae at exposure $\times 100 \%$, indicated with points) and is presented on the right axis. Error bars represent \pm 1 standard error.

Prior to statistical analysis, $\mathrm{O}_{2}$ consumption $(\mathrm{ml} / \mathrm{hr})$ of each tadpole was plotted by time and examined for activity peaks, factors which bias estimates of SMR. Based on visual inspection of these plots, the lowest quartile value was used to estimate SMR for each individual (Hopkins et al., 2004). The influence of parasite infection on SMR (log transformed) during the infection and 1 mo PI trials was determined using multiple linear regression with the number of metacercariae and log transformed mass as independent variables. Simple linear regression was used to determine the relationship between mass and SMR in the pre-infection trial. To determine if the relationship between infection and SMR (log transformed) changed among the 3 respirometry trials, the slope of the relationship at each trial was estimated, and then an ANOVA was used to test for differences among slopes.

Variability in intestine wet mass, dry mass, and length were each analyzed by multiple linear regression, with the number of metacercariae and $\log$ transformed mass as independent variables in each model.

The distribution of metacercariae recovered from the individual kidneys was analyzed by a series of Chi-square analyses, assuming a completely random distribution, equal distribution between pronephros and mesonephros, and equal distribution on the right and left side.

\section{RESULTS}

\section{Parasite encystment}

The fasted mass of tadpoles before infection did not differ among treatments $(P=0.996)$. The parasite treatment levels of 10,30 , and 90 cercariae resulted in statistically significant differences in the number of encysted metacercariae recovered from the tadpole kidneys $\left(F_{2,35}=437.906, P<0.001\right.$; Fig. 1$)$. No metacercariae were detected in any of the control tadpoles. The percent of cercariae recovered as metacercariae from individual tadpoles ranged from $10-100 \%$, but treatment means ranged from $65-72 \%$ and did not differ significantly among treatments $\left(F_{2,35}=\right.$ $0.463, P=0.634$; Fig. 1$)$.

\section{Survival, growth, and development}

All tadpoles survived to the end of the experiment, 2 mo PI. In addition, no cases of edema occurred, a common response to $E$. trivolvis infection (Fried et al., 1997; Holland, 2007). The number of metacercariae did not significantly affect final, fasted tadpole body mass $(P=0.653$; Fig. 2$)$. The developmental stages of the 


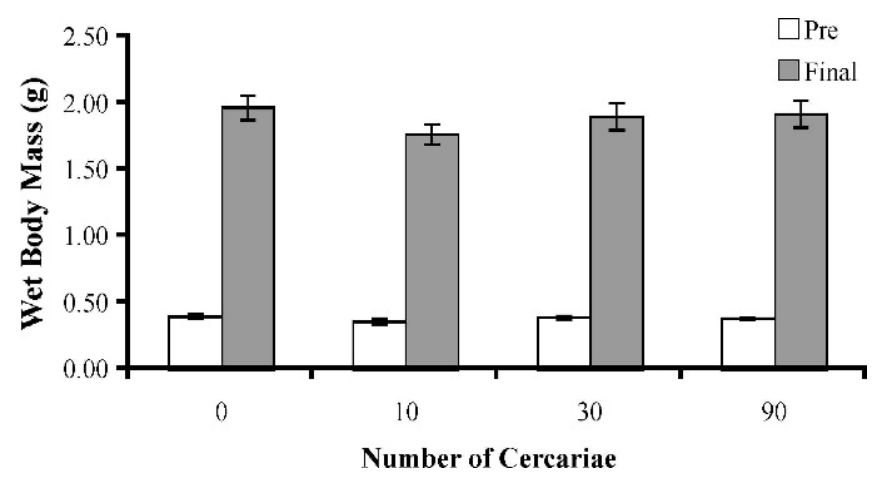

Figure 2. Average fasted mass of Rana palustris tadpoles ( $\mathrm{n}=12$ per treatment), pre-infection (white bars) and 58 days PI (grey bars), presented as treatment groups based on cercarial exposure levels. Error bars represent \pm 1 standard error.

tadpoles were similar among treatments, ranging from 26-28 at infection, 29-35 at 1 mo PI, and 35-40 at 2 mo PI (Gosner, 1960). The number of metacercariae did not significantly affect the developmental stage of tadpoles 2 mo PI $(P=0.218)$; however, tadpole mass and developmental stage were strongly correlated $(P$ $<0.001)$.

\section{Energetics}

The number of metacercariae encysted did not influence the metabolic rate of tadpoles (Fig. 3). The number of metacercariae did not have a significant effect on SMR measured during the infection $(P=0.105)$ or at 1 mo PI $(P=0.907)$. Because larger tadpoles had higher SMRs, there was a significant effect of logtransformed mass on SMR prior to infection $(P<0.001)$, during infection $(P<0.001)$, and at 1 mo PI $(P<0.001)$.

\section{Intestine size}

The number of metacercariae encysting did not have a significant effect on the wet mass (mean \pm SE $=0.270 \pm$ $0.011 \mathrm{~g} ; P=0.283$ ) or dry mass of the intestine (mean $\pm \mathrm{SE}=$ $0.026 \pm 0.001 \mathrm{~g} ; P=0.727)$. Likewise, the number of

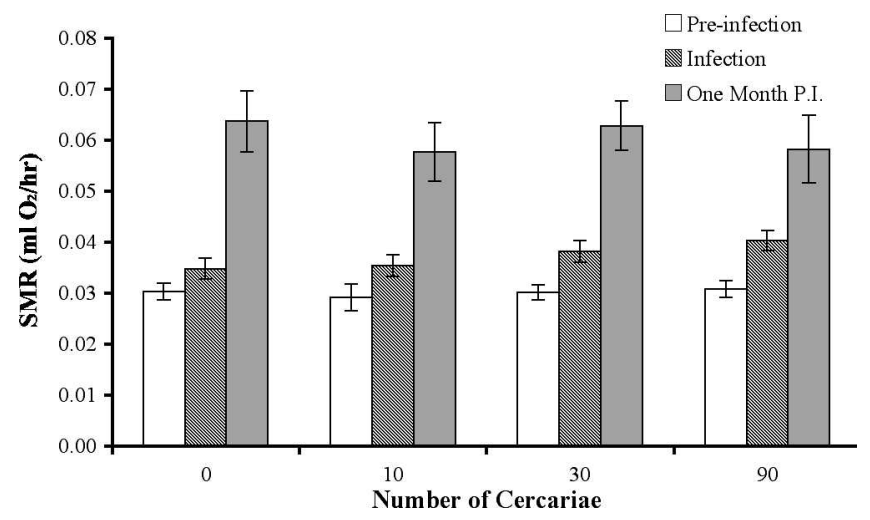

FIgURE 3. Average standard metabolic rate (SMR) of Rana palustris tadpoles ( $\mathrm{n}=12$ per treatment) presented as treatment groups based on cercariae exposure levels pre-infection (white bars), during infection (striped bars), and 1 mo PI (light gray bars). Error bars represent \pm 1 standard error.
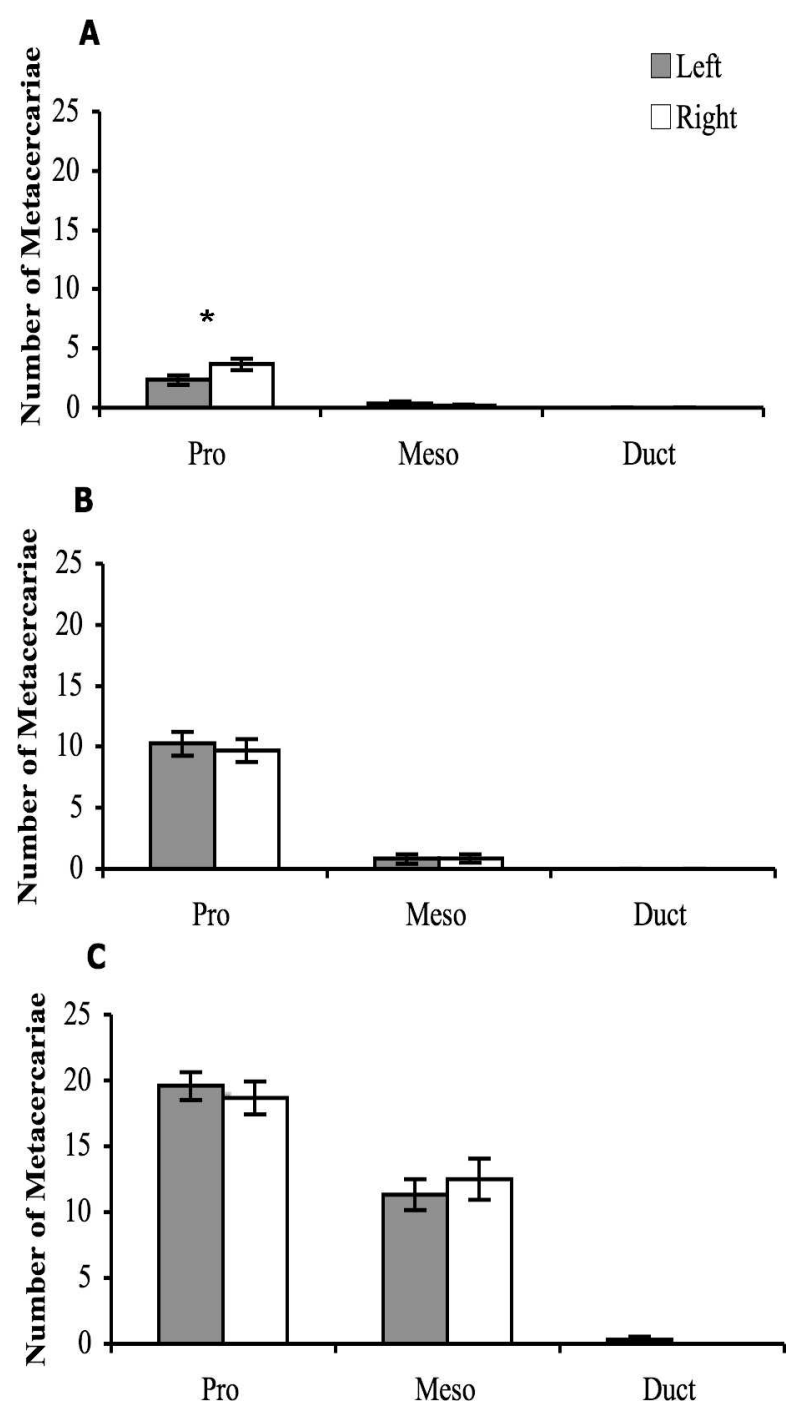

Figure 4. Average number of Echinostoma trivolvis metacercariae recovered from the pronephros (Pro), mesonephros (Meso), and Wolffian duct (Duct) on the right (white bars) or left (gray bars) of Rana palustris tadpoles ( $\mathrm{n}=12)$ exposed to (A) 10 cercariae, (B) 30 cercariae, or (C) 90 cercariae. Error bars represent \pm 1 standard error. *Asterisk identifies a statistically significant difference, $P<0.05$.

metacercariae did not have a significant effect on intestine length (mean $\pm \mathrm{SE}=233 \pm 5 \mathrm{~mm} ; P=0.425$ ). Log-transformed body mass explained a significant amount of the variation in each intestine measurement $(P<0.001)$.

\section{Parasite distribution}

Echinostoma trivolvis metacercariae were not equally distributed within the pronephros and mesonephros tissues. The majority of encystment occurred in the pronephros (10 cercariae, $\chi^{2}=$ 56.35, $P<0.001 ; 30$ cercariae, $\chi^{2}=185.18, P<0.001 ; 90$ cercariae, $\left.\chi^{2}=41.06, P<0.001\right)$. The encystment of metacercariae showed a significant bias for the right side in the tadpoles exposed to the low treatment of 10 cercariae, but not in the other 2 treatments (10 cercariae, $\chi^{2}=4.22, P=0.040 ; 30$ cercariae, $\chi^{2}$ $=0.205, P=0.651 ; 90$ cercariae, $\chi^{2}=0.949, P=0.330$; Fig. 4). 


\section{DISCUSSION}

Amphibian parasites, including E. trivolvis, have received attention recently because of the potential contribution of disease to amphibian population declines (Daszak et al., 2003; Stuart et al., 2004). However, effects of parasite infection that approximate predominant natural infection levels, and timing of infection, require further investigation (Schotthoefer et al., 2003). In our study, infection levels were selected to approximate those that are likely most common in nature. At these levels, E. trivolvis infection had no effect on survival, growth, or development of tadpoles, suggesting that the modest metacercariae infection that tadpoles likely have in most natural populations has little impact on individual tadpole fitness in the absence of other biotic or abiotic challenges.

Consistent with these growth results, tadpole SMR also was not significantly affected by encysted metacercariae either during infection or at $1 \mathrm{mo}$ PI. Our study is the first attempt to investigate metabolic changes in tadpoles as a physiological response to sub-lethal trematode metacercariae infection (Martin and Conn, 1990; Holland et al., 2007). Energetics may underlie the mortality and decreased growth observed in studies of individuals bearing higher parasite burdens and, thus, should be an important mechanistic consideration in further studies of amphibian-parasite interactions in the environment. For example, the growing environmental challenge of eutrophication leads to increased infection rates (Johnson et al., 2007), but may also provide algal food resources that would allow tadpoles to maximize energy acquisition, even if metabolic demands were elevated by infection (Belden, 2006).

Tadpole age, size, and developmental stage at the time of infection might mitigate the impact of infection. Our moderate infection was coupled with timing of infection to size and developmental stages when $R$. palustris would most likely encounter trematodes in nature. The older, larger tadpoles in our study may have larger pronephros that may be more resilient to pathology and, therefore, buffered against the loss of functional tissue (Fox, 1963). The absence of edema after infection is consistent with this proposed resilience. If a threshold level of destruction is not reached, kidney function and tadpole survival and growth may remain unaltered (Goater, 1994; Belden, 2006). Early experiments, removing single pronephros from tadpoles with minimal effects on growth, support the hypothesis that a substantial portion of the kidney needs to be affected before growth is inhibited (Fox, 1963).

Our study also addressed the novel idea that tadpoles may mitigate the effects of parasitism by altering the gross morphology of the intestines. Phenotypic plasticity of organ sizes has been shown in trematode-infected mammals (Kristan and Hammond, 2000; Schwanz, 2006), but this phenomenon has never been examined in amphibians. Tadpoles respond to predation and competition through changes in intestinal morphology (Relyea and Auld, 2004), but we did not detect any effect of parasitism on intestine size. However, we predicted such changes would only occur if energy demands were elevated which, based on the SMR results, does not seem to be the case. In addition, generous rations provided to individually maintained tadpoles might have hindered our ability to detect intestinal plasticity because it eliminated the need to develop a more-efficient digestive system to maintain optimal growth rates (Munger and Karasov, 1989). Therefore, we postulate that plasticity of the intestines remains a plausible response to parasitism in tadpoles.

Echinostoma trivolvis metacercariae encyst in specific sites within the nephric system depending on tadpole age and developmental stage (Thiemann and Wassersug, 2000; Schotthoefer et al., 2003), which may reduce impact on the host by localizing the pathology. Cercariae infecting stage 26-28 (Gosner, 1960) $R$. palustris tadpoles encysted in the pronephros in higher numbers than in the mesonephros, and cercariae exhibited a bias for the right kidney at the lowest infection level. Higher encystment within the pronephros than in the mesonephros is consistent with experimental studies of $R$. pipiens and $R$. clamitans tadpoles at similar developmental stages (Thiemann and Wassersug, 2000; Schotthoefer et al., 2003). The trend of biased encystment in the pronephros was not as pronounced at higher infection levels, suggesting that the mesonephros, while not the preferred encystment location, may have been of sufficient size to support at least some metacercariae (Schotthoefer et al., 2003), or may simply be the location of encystment when space is no longer available in the pronephros.

Our study focused on moderate infection levels because a significant proportion of the population may encounter these levels. Under our experimental conditions, moderate infections in this species did not elicit a significant effect on survival, growth, development, or respiration. If fitness-related traits are only negatively affected by higher infection levels, only a small proportion of the population may be impacted. However, anthropogenic stressors such as climate change (Poulin, 2006), eutrophication (Johnson et al., 2007), and environmental contamination (Kiesecker, 2002; Gendron et al., 2003) may increase infection rates and shift the timing of infection so that morevulnerable individuals are infected more severely. In addition, characteristics of the environment, such as limited food resources and the presence of competitors and predators, may interact with parasite infection to result in additive or synergistic effects on developing amphibians. Monitoring of natural infection levels, and continued investigation of amphibian-parasite dynamics at levels relevant for the majority of the population, will help determine whether anthropogenic changes are having a negative impact on amphibian populations by influencing parasite-host interactions.

\section{ACKNOWLEDGMENTS}

This study was supported by startup funding from Virginia Tech and by the National Science Foundation (NSF IOB-0615361) to W.A.H. and an NSF Graduate Research Fellowship to S.A.O. Additional support was provided by a Grant-In-Aid of Research from Sigma Xi to S.A.O. The authors are grateful to P. M. Dixon for statistical advice. The authors also thank N. A. Peterson, J. M. Orlofske, R. C. Jadin, S. A. Budischak, and two anonymous reviewers for comments on the manuscript. This research was conducted under 07-021-FIW and approved by the Virginia Tech Institutional Animal Care and Use Committee.

\section{LITERATURE CITED}

BeAver, P. C. 1937. Experimental studies on Echinostoma revolutum (Froelich), a fluke from birds and mammals. Illinois Biological Monographs 15: 1-96.

Belden, L. K. 2006. Impact of eutrophication on wood frog, Rana sylvatica, tadpoles infected with Echinostoma trivolvis cercariae. Canadian Journal of Zoology 84: 1315-1321.

- AND J. M. KIESECKER. 2005. Glucocorticosteroid hormone treatment of larval treefrogs increases infection by Alaria sp. trematode cercariae. Journal of Parasitology 91: 686-688. 
Crowder, W. C., M. Nie, and G. R. Ultsch. 1998. Oxygen uptake in bullfrog tadpoles (Rana catesbeiana). Journal of Experimental Zoology 280: 121-134.

Daszak, P., A. A. Cunningham, and A. D. Hyatt. 2003. Infectious disease and amphibian population declines. Diversity and Distributions 9: 141-150.

Esch, G. W., M. A. Barger, and K. J. Fellis. 2002. Transmission of digenetic trematodes: Style, elegance, complexity. Integrative and Comparative Biology 42: 304-312.

Faeh, S. A., D. K. Nichols, and V. R. Beasley. 1998. Infectious diseases of amphibians. In Status and conservation of midwestern amphibians, M. J. Lannoo (ed.). University of Iowa Press, Iowa City, Iowa, p. $259-265$.

Fox, H. 1963. The amphibian pronephros. Quarterly Review of Biology 38: $1-25$.

FrIED, B. 1997. An overview of the biology of trematodes. In Advances in trematode biology, B. Fried and T. K. Graczyk (eds.). CRC Press, Boca Raton, Florida, p. 12-13.

- AND J. D. BRADFORD. 1997. In vitro excystation of metacercarial cysts of Echinostoma trivolvis from Rana species tadpoles. The Korean Journal of Parasitology 35: 75-77.

_ P. L. PANe, ANd A. Reddy. 1997. Experimental infection of Rana pipiens tadpoles with Echinostoma trivolvis cercariae. Parasitology Research 83: 666-669.

Gendron, A. D., D. J. Marcogliese, S. Barbeau, M.-S. Christin, P. Brousseau, S. Ruby, D. Cyr, and M. Fourinier. 2003. Exposure of leopard frogs to a pesticide mixture affects life history characteristics of the lungworm Rhabdias ranae. Oecologia 135: 469-476.

Goater, C. P. 1994. Growth and survival of postmetamorphic toads: Interactions among larval history, density, and parasitism. Ecology 75: $2264-2274$.

Gosner, K. L. 1960. A simplified table for staging anuran embryos and larvae with notes on identification. Herpetologica 16: 183-190.

Holland, M. P., D. K. Skelly, M. Kashgarian, S. R. Bolden, L. M. Harrison, and M. Cappello. 2007. Echinostome infection in green frogs (Rana clamitans) is stage and age dependent. Journal of Zoology 271: 455-462.

Hopkins, W. A., J. H. Roe, T. Philippi, and J. D. Congdon. 2004. Standard and digestive metabolism in the banded water snake, Nerodia fasciata fasciata. Comparative Biochemistry and Physiology Part A 137: 141-149.

Johnson, P. T. J., J. M. Chase, K. L. Dosch, R. B. Hartson, J. A. Gross, D. J. Larson, D. R. Sutherland, and S. R. Carpenter. 2007. Aquatic eutrophication promotes pathogenic infection in amphibians. Proceedings of the National Academy of Science USA 104: $15781-15786$

, AND K. B. Lunde. 2005. Parasite infection and limb malformations: A growing problem in amphibian conservation. In Amphibian declines: The conservation status of United States species, M. Lannoo (ed.). University of California Press, Berkeley, California, p. 124-138. , R. W. Haight, J. Bowerman, and A. R. Blaustein. 2001. Ribeiroia ondatrae (Trematoda: Digenea) infection induces severe limb malformations in western toads (Bufo boreas). Canadian Journal of Zoology 79: 370-379.

, E. G. Ritchie, and A. E. Launer. 1999. The effect of trematode infection on amphibian limb development and survivorship. Science 284: 802-804.

E. M. Thurman, E. G. Ritchie, S. N. Wray, D. R. Sutherland, J. M. Kapfer, T. J. Frest, J. Bowerman, and A. R. Blaustein. 2002. Parasite (Ribeiroia ondatrae) infection linked to amphibian malformations in the western United States. Ecological Monographs 72: 151-168.

- ANd D. R. Sutherland. 2003. Amphibian deformities and Ribeiroia infection: An emerging helminthiasis. Trends in Parasitology 19: 332-335.

Kanev, I., B. Fried, V. Dimitrov, And V. Radev. 1995. Redescription of Echinostoma trivolvis (Cort, 1914) (Trematoda: Echinostomatidae) with a discussion on its identity. Systematic Parasitology 32: 61-70.

KIESECKER, J. M. 2002. Synergism between trematode infection and pesticide exposure: A link to amphibian limb deformities in nature? Proceedings of the National Academy of Sciences USA 99: 99009904.
KoprivnikAR, J., M. R. Forbes, AND R. L. BAKER. 2008. Larval amphibian growth and development under varying density: Are parasitized individuals poor competitors? Oecologia 155: 641-649.

Kristan, D. M., and K. A. Hammond. 2003. Combined effects of cold exposure and sub-lethal intestinal parasites on host morphology and physiology. Journal of Experimental Biology 203: 3495-3504.

Lemly, A. D., AND G. W. Esch. 1984. Effects of the trematode Uvulifer ambloplitis on juvenile bluegill sunfish, Lepomis macrochirus: Ecological implications. Journal of Parasitology 70: 475-492.

Martin, T. R., AND D. B. ConN. 1990. The pathogenicity, localization, and cyst structure of echinostomatid metacercariae (Trematoda) infecting the kidneys of the frogs Rana clamitans and Rana pipiens. Journal of Parasitology 76: 414-419.

McCluRe, C. F. W. 1919. On the experimental production of edema in larval and adult anura. Journal of General Physiology 1: 261-267.

Munger, J. C., AND W. H. Karasov. 1989. Sublethal parasites and host energy budgets: Tapeworm infection in white-footed mice. Ecology 70: $904-921$.

Penchenik, J. A., ANd B. Fried. 1995. Effect of temperature on survival and infectivity of Echinostoma trivolvis cercariae: A test of the energy limitation hypothesis. Parasitology 111: 373-378.

Peterson, N. A. 2007. Seasonal prevalence of Ribeiroia ondatrae in one population of Planorbella trivolvis (= Helisoma trivolvis), including notes on the larval trematode component community. Comparative Parasitology 74: 312-318.

Poulin, R. 2006. Global warming and temperature-mediated increases in cercarial emergence in trematode parasites. Parasitology 132: 1-9.

Relyea, R. A., AND J. R. Auld. 2004. Having the guts to compete: How intestinal plasticity explains costs of inducible defenses. Ecology Letters 7: 869-875.

Roe, J. H., W. A. Hopkins, J. W. Snodgrass, and J. D. Congdon. 2004. The influence of circadian rhythms on pre- and post-prandial metabolism in the snake Lamprophis fuliginosus. Comparative Biochemistry and Physiology, Part A 139: 159-168.

SChMidT, K. A., AND B. Fried. 1996a. Experimental infection of Helisoma trivolvis (Colorado strain) snails with cercariae of Echinostoma trivolvis. International Journal for Parasitology 26: 287-289.

- AND . 1996b. Emergence of cercariae of Echinostoma trivolvis from Helisoma trivolvis under different conditions. Journal of Parasitology 82: 674-676.

Schotthoefer, A. M., R. Cole, And V. R. BeAsley. 2003. Relationship of tadpole stage to location of echinostome cercariae encystment and the consequences for tadpole survival. Journal of Parasitology 89: 475482.

Schwanz, L. E. 2006. Schistosome infection in deer mice (Peromyscus maniculatus): Impacts on host physiology, behavior, and energetics. The Journal of Experimental Biology 209: 5029-5037.

Shaw, D. J., B. T. Grenfell, and A. P. Dobson. 1998. Patterns of macroparasite aggregation in wildlife host populations. Parasitology 117: 597-610.

Sibly, R. M. 1981. Strategies of digestion and defecation. In Physiological ecology: An evolutionary approach to resource use, C. R. Townsend and P. Calow (eds.). Blackwell, Oxford, U.K., p. 109-139.

Skelly, D. K., S. R. Bolden, M. P. Holland, L. K. Freidenburg, N. A Friedenfelds, AND T. R. Malcolm. 2006. Urbanization and disease in amphibians. In Disease ecology: Community structure and pathogen dynamics, S. K. Collinge and C. Ray (eds.). Oxford University Press, Cary, North Carolina, p. 153-167.

Steyermark, A. C., A. G. Miamen, H. S. Feghahati, and A. W. Lewno. 2005. Physiological and morphological correlates of among-individual variation in standard metabolic rate in the leopard frog Rana pipiens. Journal of Experimental Biology 208: 1201-1208.

Stuart, S. N., J. S. Chanson, N. A. Cox, B. E. Young, A. S. L. Rodrigues, D. L. Fischman, and R. W. Waller. 2004. Status and trends of amphibian declines and extinctions worldwide. Science 306: $1783-1786$.

Taylor, C. N., K. L. Oseen, and R. J. Wassersug. 2004. On the behavioural response of Rana and Bufo tadpoles to echinostomatoid cercariae: Implications to synergistic factors influencing trematode infections in anurans. Canadian Journal of Zoology 82: 701-706.

Thiemann, G. W., and R. J. Wassersug. 2000. Biased distribution of trematode metacercariae in the nephric system of Rana tadpoles. Journal of the Zoological Society of London 252: 534-538. 